\title{
UNCERTAINTY AND THE POLITICS OF TRANSFORMATION
}

\author{
Ian Scoones and Andy Stirling
}

\section{Opening up the politics of uncertainty}

Why is the idea of uncertainty so important to politics today? ${ }^{1}$ Why is it especially significant for crucial debates about transformations to sustainability? This book tackles these big questions by exploring the politics of uncertainty across a range of domains and diverse case studies.

The book argues that the embracing of uncertainties - as constructions of knowledge, materiality, experience, embodiment and practice - means challenging singular notions of modernity and progress as a hard-wired 'one-track' 'race to the future'. Ideas of development and sustainability are very often associated with a linear perspective on progress, dominated by narrow views of science and economics (Folbre et al.2018). As a result of this, there is often a reliance on simplistic notions of innovation, focusing on those 'lagging behind', who must 'catch up' or 'leapfrog' to where others have reached. In this way, the framing of innovation and progress is reduced to merely how much, how fast, who is ahead and what is the risk of proceeding along an assumed pathway. Such debates too often ignore more important political questions about which way, what direction and who wins and who loses, where issues of uncertainty are central (Stirling 2015). Given diverse uncertainties, there is no single assumed endpoint; no one version of modernity and progress, and so directions chosen in the pursuit of sustainability and development depend on political and social choice (Scoones 2016).

Too often, ideas of transformation and sustainability are framed around particular, expert-defined 'solutions', with uncertainties blanked out. Typically asserted with great confidence, burgeoning notions around, for example, 'smart cities', 'climate-smart agriculture', 'clean development', 'geo-engineering', 'green growth' or 'zero-carbon economies' act to suppress appreciation of many forms of uncertainty. Conceived in narrow, technical terms, informed by relatively homogeneous, 
specialist views, these core organising ideas for high-level global policy-making typically emphasise aspiring control, asserting romantic visions of visionary leadership, heroic expertise, deterministic systems, orderly values, convergent interests, compliant citizens and expediently predictable futures.

As a consequence, some highly uncertain issues that should remain open for political debate are imagined in circumscribed, biased and one-directional ways. The loudest voices and most powerful interests thus come to enjoy a disproportionate influence in defining what is meant by 'progress'. The contrast could hardly be greater with the potentially open arena for political deliberation constituted by the United Nations' Sustainable Development Goals. Arguably, for the first time in history, these establish a globally-shared discourse enabling the exercise of agency not only over the possibility of progress but also with regard to its direction. The general orientation is clear - towards equality, well-being and ecological integrity; but the particularities of what these values might mean in practice - and how best to go about realising them - remain deeply uncertain.

Why this matters is that a rich and open-ended array of far wider, deeper and more plural kinds of possible societal, cultural and political transformations get obscured (Scoones et al. 2015). These many closures of uncertainties in mainstream, global discourses around science, technology and social progress typically serve to suppress the interests of the most marginalised communities, cultures and environments. Such failures to embrace uncertainty can presage perhaps the gravest form of oppression in the world today: the invisible foreclosing of possible futures. As a result, we argue, the opening up of political space to confront radical uncertainty can become as crucial to emancipatory politics as many more direct assertions of neglected interests.

Uncertainties are inevitable in this negotiation of diverse, possible futures concerning different pathways and their consequences (Leach et al. 2010). Uncertainties should not be reduced to risk, framed as a zero-sum threat that is in need of taming, controlling and managing, lest innovation is somehow 'held back' (Kearnes and Wynne 2007). In today's complex, turbulent, interconnected, globalised world, uncertainty must be embraced as perhaps more central than ever. We argue that opening up to uncertainty offers opportunity, diversity and a politics of hope. This in turn offers a more plural vision of progress, defined according to different standpoints, with multiple modernities at play.

The hegemonic ideas of linear progress and modernist development that so dominate Western cultures have been exported to the world through waves of colonialism, trade and aid. This 'globalising modernity' (Ahuja 2009; Hobden 2002) is of course not fixed. Indeed, even in the West, past ideas of progress have been framed differently: for example, around cycles of growth and renewal, rather than linear change (Cowen and Shenton 1996). In non-Western cultures, notions of development, progress and modernity often have very different connotations, rooted in subaltern identities and cultural and religious perspectives (Oxley, Chapter 12). This book argues that this globalising version of modernity and progress need not colonise the future in the ways it is presently doing. Instead, a more diverse, plural and 
contingent perspective can be advocated, involving an appreciation of uncertainty and its diverse framings.

The book reflects on different cases in different settings, each offering narratives about the future, with uncertainty central to the storyline. The chapters focus on banking and finance; insurance systems; the regulation of technology; critical infrastructures; cities; climate change; disease outbreaks; natural disasters; migration flows; crime and terrorism and spirituality and religion. All suggest that the contemporary moment poses fundamental challenges to the status quo. Old assumptions of linear, stable systems, amenable to technical risk management and control, do not hold.

This challenges the globalising modernity of (neo)liberal capitalism - with its pretence of stable environments and economies, and assertion of particular cultures of expertise and structures of appropriation and control. Futures are unknown: even when seen from any individual viewpoint, uncertainties are ubiquitous. Diverging interests and perspectives introduce further ambiguities. Underlying all this is the radical, ever-present potentiality of downright ignorance and surprise. Today, financial instability, pandemic disease, climate chaos, recurrent natural disasters and threats to liberal, 'democratic' orders across the world are refashioning the ways policy, politics and governance are thought about. Arguing that uncertainty in all its forms is central, this book suggests a new politics of uncertainty: one that offers opportunities, but also dangers.

The stakes could hardly be higher. On the one hand, the landscape of possible futures for globalising forms of modernity suggest trends towards narrow, technocratic, fearful, risk-focused intensifications of control. On the other hand, subaltern, 'alternative' (Kaup 2012; Gaonkar 1999) and 'minoritarian' modernities (Taraborrelli 2015) - as well as wider emerging 'non-modernities' (Ibarra-Colado 2006) - offer imaginings of new institutions and practices for embracing - even celebrating - uncertainty. It is arguably through more equal engagements between these diverse cultural, political and organisational forms that space can be found for a more plural, mutualistic and hopeful politics of care and conviviality (Stirling 2019b; Arora 2019; cf. Illich 1973).

\section{From framings to practices of uncertainty}

Uncertainties are not merely about the absence of knowledge (Walker et al. 2003): they can be very concrete - and formatively diverse - in their manifestations. The literatures on uncertainty span many different disciplines, applied to a diversity of domains (Scoones 2019), but a key distinction - highlighted long ago by Frank Knight (1921) - is that between risk and uncertainty. Risk is where we know what the possible outcomes are and can estimate their probabilities. Uncertainty is where we are unsure of the probabilities of particular outcomes. This is important, as there is too often a tendency to 'close down' towards risk (Stirling 2008), pretending to know the probabilities. Yet this is often not realistic in practice, as models and estimates are confounded by uncertainties. In cases where systems are 
complex, interacting and non-linear, a narrow engineering risk-based approach is inappropriate.

A number of other dimensions of incertitude also arise. These include ambiguities - where there are ongoing disputes about possible outcomes between different groups, reflecting contending social and political worlds (Stirling 1999). Here, for instance, it may be that debates do not mainly concern how likely different outcomes may be, but are about more fundamentally divergent notions of 'benefit' or 'harm', or their distribution across society, or what the alternative options for action may be. There is also the predicament of ignorance, where fundamental indeterminacies of the world and 'non-knowledge' mean we 'don't know what we don't know' (Wynne 1992). And here it is important to remember that surprises can of course be positive as well as negative, depending on who is affected.

Under routine conditions, narrow notions of risk can remain useful in the engineering of closed systems, or where high-frequency, unchanging processes generate long-run comparable statistics. Here, there is no need to throw away the baby with the bathwater. But even where all parameters are well-known, most conditions in the world are uncertain, with specific probabilities and/or outcomes remaining not known or unknowable. And where there is even the possibility of unknown parameters, then ignorance is unavoidable. All these cumulative dilemmas have profound consequences, as the chapters in this book explore. The bottom line, in many circumstances, is that the assumptions of a risk-based approach can be inappropriate, misleading - and even dangerous.

Uncertainties therefore are conditions of knowledge itself - how we understand, frame and construct possible futures - and are not just hard-wired into 'objective' situations. But uncertainties also have other features, beyond these epistemological and ontological implications. Across the chapters of this book, four additional dimensions are discussed:

- Uncertainties have concrete, material features. They are produced from complex, non-linear unpredictable systems (Driebe and McDaniel 2005). They have material origins and effects. For example, the environmental variability of rangelands may be a source of productive advantage for pastoralists as they move across landscapes harvesting nutrients - living with and from uncertainty (Krätli and Schareika 2010). In complex systems, surprises - sudden 'black swan' events - may arise that were never expected (Taleb 2007). Taming and controlling such systems is impossible, but understanding and responding to unpredictable variability is vital (Funtowicz and Ravetz 1990), requiring invention of new forms of science, regulation and management (van Zwanenberg, Chapter 4; Roe, Chapter 5).

- Uncertainties are not experienced in the same way by different people. Knowledges about the present and perspectives on the future are all constructed in particular contexts. Depending on one's situation, uncertainties may be embraced as an opportunity or encountered as a source of dread, fear and anxiety. An experiential, affective stance on uncertainty is therefore 
unavoidable. Emotions and feelings matter, as they affect understanding and action. Religious and spiritual beliefs about - and enactment of - relationships between humans and the world may also impinge (Skrimshire 2014; Oxley, Chapter 12), as in Samkhya Hindu philosophy, which offers a plural perspective on understanding, influenced by consciousness, perception and experience. ${ }^{2}$ And, in turn, uncertainties are influenced by histories, cultures and identities, as social worlds and historical experiences filter perspectives and condition action (Da Col and Humphrey 2012). Thus, marginalised communities in the global South will experience climate shocks in very different ways to privileged groups in the North, as histories of colonialism and dispossession influence what is possible and how pasts, presents and futures are viewed (Watts and Bohle 1993).

- Perspectives on uncertainties are also embodied, becoming part of who we are, as well as how we think and feel (Csordas and Harwod 1994). Sometimes this is physically reflected in our bodies. For example, men and women, and young and old people, may respond to the uncertainties of climatic or other disasters quite differently, as a result of the consequences of events in their day-to-day lives (Sword-Daniels et al. 2018). School children may find debates about climate change unsettling and anxiety-inducing, especially when 'facts' are unclear, ${ }^{3}$ while living with a chronic illness may result in a very different outlook to those of medical professionals and even family members, as both the condition and its treatment are enacted through the body (Mol and Law 2004). Drawing on feminist and queer theory, Wendy Harcourt (2013) argues that the body plays an important - often hidden and contested - role in the ways we encounter the world, and conduct 'development'. As with 'tacit knowledge', embodied uncertainties remain entirely undocumented and even not consciously apprehended by those most intimately affected, making them especially significant when addressing responses to incertitude.

- Finally, our understandings of uncertainty are reflected in practices: how we act, and the type of social imaginaries we construct - or which emerge unintentionally - serve to guide our lives and politics (Arora and Glover 2017; Shove et al. 2012). In response, emerging practices include both controlling forms of 'audit culture' (Power 2004), as well as more flexible, adaptive forms of 'reliability management' (Roe 2013; Roe, Chapter 5). During the financial crisis, it was the practical responses of financial regulators, supervisors and traders that helped avoid total collapse. According to Ilene Grabel, this was due to features of 'productive incoherence' and 'pragmatic innovation' in the financial system (Grabel 2017). A focus on agency, and more distributed possibilities for action, directs attention towards relations of power in responding to uncertainty. Michael Thompson and Michael Warburton, for example, explored power dynamics around deep uncertainties over deforestation and river management in the Himalayas - tracking moves within discourse away from 'what the facts are' towards a focus on what powerful interests 'would like the facts to be'. In this way, the agency of incumbent interests behind major infrastructure 
proposals was reinforced, while that of less powerful actors - like mountaindwelling subsistence farmers - was denigrated (Thompson and Gyawali 2007; Thompson and Warburton 1985).

A diverse appreciation of these five dimensions of uncertainty suggests a challenge to the controlling, managerial policy responses that have been the hallmark of technocratic modernity - and, for some, diagnostic of progress. However, as a number of this book's chapters discuss, alternative policy and management approaches have been proposed, ranging from adaptive management (Tompkins and Adger 2004) to experimentalist approaches (Sabel and Zeitlin 2010) to deliberative governance (Dryzek 2012). Central to these are the principles of incremental learning and the negotiation of outcomes along complex, plural pathways. Deliberation, negotiation and inclusive engagement across diverse knowledges and experiences is essential. As the following chapters show through varied examples, this requires an opening up to options and knowledges, and across all aspects of incertitude - including uncertainties in the strict sense, as well as ignorance and ambiguities following our earlier categorisation. Incertitude must therefore be embraced equally in relation to knowledge, materialities, experiences, embodiment and practice.

Yet, as Mary Douglas famously identified, the same apparent 'objective' conditions of uncertainty can be lived in and worked with in very different ways by different people (Douglas 1986). Uncertainties, she argued, are constituted very differently - for instance - in hierarchical or egalitarian social orders, or collectivist or individualist institutional cultures (Thompson et al. 1990). Likewise, for the influential German sociologist Niklas Luhmann (1993), it is contrasting practical systems of communication that bring uncertainties to material life. Rather than being seen as external 'states of the world', uncertainties are therefore better understood as the messy gaps, wrinkles and tangles that serve to make societies aware of and reflexive in relation to - their own conditions of being. And, for the leading theorist of the 'risk society', Ulrich Beck, it is through uncertainties - more than professed knowledge - that contemporary societies most concretely encounter the cumulative contradictions of modernity in which they are embedded (Adam et al. 2000; Beck et al. 1994; Beck 1992).

Like Beck, the contributors to this book see risk and uncertainty as formative of contemporary politics (Mythen et al. 2018). Indeterminacy and non-knowledge fundamentally shape political and managerial possibilities. As discussed further below, the premises of many favoured policy frameworks - from equilibrium economics (Raworth 2017) to audit-based management (Power 2004) to economic regulation (Bronk and Jacoby 2016) to security regimes (Amoore 2013; Dillon 2007) to insurance provision (Ewald 1991) - become incompatible with embracing the full implications of uncertainty. Challenges to such frameworks emerge especially when looking at issues and geographies beyond Beck's original concern with individualised risks associated with accelerating industrial modernity in northern Europe (Caplan 2000). While uncertainties certainly reconfigure politics, they do so in diverse ways. As the various chapters show, class, gender, ethnicity, age and location matter in 
how uncertainties are understood and responded to (Curran 2018). A focus on uncertainty should therefore not divert attention from long-standing perspectives on social change, but instead highlight new dynamics (Carrapico et al., Chapter 11)

As a challenge to a control-oriented technocratic order of globalising modernity, we argue that a focus on the politics of uncertainty is essential. This confronts the linear assumption that a universalised science creates technologies for singular progress, suggesting instead a more diverse, plural vision, implicating multiple modernities. Indeed, as uncertainties reconfigure politics, we can observe different effects. Uncertainty can create anxiety and fear, and open spaces for rent-seeking, profitmaking and forms of populist authoritarianism (Scoones et al. 2018), while at the same time it can offer hope - and spaces for experimentation and learning that can lead to an emancipatory politics for the future (Solnit 2016). As the chapters discuss - across a diversity of domains - which directions are taken, and how institutions of science, law and the state respond, are crucial issues for our times (Nowotny 2015).

\section{Topologies of uncertainty}

Interweaving through these wider currents are the more specific dimensions of uncertainty explored in the chapters of this book. Just as quantification of any kind is always underlain by qualitative dimensions, so all the different arcane geometries of 'risk' and 'probability' are always shaped by the topologies of uncertainty on which they are built. So, the structures of possibility underpinning commerce, banking and finance are potentially formative of entire wider economies, and deeply influenced by the narratives of economics and the forms of modelling of uncertainty that are deployed (Walter and Wansleben, Chapter 2). Beyond the particular actuarial expediencies, it is the imagined relationships between presents and futures that make insurance so generative of everyday life, and that explain why regarding rigid forms of insurance as routes to social protection becomes problematic under conditions of uncertainty and ignorance (Johnson, Chapter 3; Taylor 2019).

Infrastructures and regulatory orders assert their own materialisations of political imaginations around technology regulation (van Zwanenberg, Chapter 4), the management of critical infrastructures (Roe, Chapter 5) and city planning (Kaker et al., Chapter 6). These chapters highlight how the practices of scientists, regulators and civil society actors can help open up indeterminacies in everything from genetically modified crop technologies to 'smart' cars; they emphasise the importance of everyday practice and network-building in generating reliability in complex critical infrastructures, such as energy systems; and they explore how more effective responses to diverse uncertainties can be nurtured through creating "experimental spaces' for innovation in urban governance (Evans et al. 2016).

Deepening global vulnerabilities around climate (Mehta and Srivastava, Chapter 7), disease (MacGregor et al., Chapter 8) and 'natural disasters' (Pelling et al., Chapter 9) create major political challenges for addressing uncertainties. Too often, there is a closing down towards narrow risk management and securitisation 
in approaches to early warning, emergency preparedness and disaster risk reduction. Yet, as these chapters show, locating understandings in a more complex appreciation of class, gender, ethnicity and age is essential if those directly affected by outbreaks, emergencies and disasters are to be involved.

The politics of uncertainty in debates over migration (Thorsen, Chapter 10), crime and terrorism (Carrapico et al., Chapter 11) also reflect highly politicised institutional constructions of risk, danger and threat. These may obscure more positive approaches by ignoring alternative framings centred on hope and possibility (Kleist and Thorsen 2016). The knee-jerk, authoritarian response is to control, instil fear, construct borders and subject people to intrusive surveillance. A more encompassing view, on the other hand, would suggest alternatives; for example, focusing on the agency, networks and capacities of migrants themselves in facing uncertainties. How then are the contested meanings and implications of uncertainty negotiated? Underlying cultural, religious and spiritual framings may be underestimated in our rush to assert technocratic orders, as discussed in our final chapter (Oxley, Chapter 12). Religious beliefs involve competing views on destiny, renewal and apocalypse, for instance, and so must continuously grapple with issues of uncertainty as framing human existence, suggesting the need for a wider, more encompassing view.

\section{From calculative control to creative care}

A classic insight that arises from non-linear systems understandings - that minor changes can make a big difference - means that simple notions of prediction and control are a myth. Yet even with this acknowledgement widely accepted (if only rhetorically), indeterminacies are too often represented in a controlling, calculative and aggregative register. How often, for example, does discussion of 'tipping points' move from humility in the face of their possibility to hubris in regard to their precise prediction, or misplaced confidence that such complex systems can be subject to 'risk management'? (Lenton et al. 2019). As a result, the crucial point about the uncontrollability of uncertainty may paradoxically be most lost when it is apparently most acknowledged.

A number of the book's chapters reflect on a wide range of models. These include the economic forecasting models used by banks (Wansleben 2014); the actuarial and parametric models central to the (re)insurance industry (Johnson 2013); the infectious disease models that predict patterns of spread and impact and the many models that aim to predict the impacts of natural hazards - from floods to volcanoes to earthquakes (Hough 2002). Here as elsewhere, modelling struggles to make sense of uncertain, complex systems, often aiming to predict future patterns. Yet again, these calculative mathematical devices and aggregative practices too often involve attempted reductions of uncertainties to risk (Hastrup and Skrydstrup 2013).

In all these areas, non-linear interactions and disequilibrium dynamics at the heart of complex systems make the necessary simplifications and assumptions of modelling approaches problematic. Offering a sense of certainty where there is 
none misleads. It may help raise awareness about a particular potential disaster and raise funds for agencies aiming to respond. But this itself may divert attention from diverse lived-with, grounded circumstances, offering instead a headline figure projecting one impending crisis. And these imperatives may also blinker key players against surprise, entrenching ideas that a risk-managed status quo will result in stability. Reflecting on the financial crash of 2008, Andy Haldane, chief economist at the Bank of England, observed:

Securitisation increased the dimensionality, and thus complexity, of the financial network. Nodes grew in size and interconnections between them multiplied. The financial cat's-cradle became dense and opaque. As a result, the precise source and location of underlying claims became anyone's guess (2009: 7).

The resulting crisis, Haldane (2010: 12) argues, was rooted in 'an exaggerated sense of knowledge and control'.

Of course, all models come with lists of provisos, caveats and qualifications, but, even with accuracy thus qualified, a key role persists in governing action. Here, the silences of models are as important as their proclamations. So in the end models are - albeit often quite elaborate - vehicles for telling stories. They equally embody and construct narratives about both present-futures and future-presents, often dressed up with arcane equations and mathematical formulations (Beckert and Bronk 2018). The narratives they relate are socially constructed, becoming accepted through often quite homogenous, uncritical networks of actors (Bronk 2019). Members of such networks all have a vested interest in maintaining an impression of control and giving a sense that collectively they have a capacity to manage complexity and define the future.

While such stories often unravel in the face of real-world events, the incumbent power of professions and their institutions - not surprisingly - soon reinstate the status quo. The last crisis is deemed an outlier, models are improved and the fragile performance of control continues in the face of uncertainty. Studies of financiers during and following the 2008 crash are instructive. The psychological imperative to construct 'conviction narratives' and deny uncertainty was evident, as the incentives for promoting positive imaginaries around fictional expectations were huge (Tuckett 2018). In the same way, misplaced concreteness in models at the centre of decision-making can be seen as a defensive mechanism used to displace anxieties around uncertain outcomes (Fenton-O'Creavy 2019).

Exercising huge power in policy processes, this process of storytelling through models is about presenting clear storylines, but also often involves moves to conceal and divert attention. Embedded assumptions typically hide normative, ethical and political positions, but because of the story's form, these appear only obliquely, or are hidden in the footnotes, acknowledgements, sensitivity analyses, funding sources and additional materials. Since models afford less audience interaction than in live storytelling, there is less accountability for the associated fictions and fallacies. 
This raises questions about who grants authority to the narrative and how this is mediated; for instance with the media filtering out the headline story and ignoring the detail (Beckert and Bronk 2018).

This combination of rhetorical and market power helps entrench institutional and policy monocultures that in their turn further reinforce the authority given to such partial knowledge (Bronk and Jacoby 2016). Banks, risk management authorities, insurance firms, civil contingency agencies, humanitarian organisations and others require such knowledge that excludes significant dimensions of uncertainty in order to function (Walter and Wansleben, Chapter 2; Johnson, Chapter 3; MacGregor et al., Chapter 8). They have the power to control narratives, stabilise expectations and define the future on their terms. These are classic hegemonic constellations that offer an illusion of control. In economics and finance, for example, commitments to the gold standard, the sanctity of the money supply and the power of equilibrium economics have, at different times, been core to belief systems, each with wide institutional and political commitments. Yet in each case, supported by powerful models with fragile assumptions, they have all been challenged and overturned (Mazzucato 2018).

In order to understand how models - and associated narratives - act to construct and colonise futures in ways that link to a wider political economy of incumbent power, we must understand their social and political lives (Appadurai 1988). This, in particular, means understanding the actors involved and their links across networks (Barthe et al. 2009). Insights from science and technology studies show processes through which particular equations and parameters become core to a model, which in turn becomes central to policy thinking. Whether these concern the epidemiologies of disease control (Leach and Scoones 2013) or constructions of financial derivatives (MacKenzie and Spears 2014), the models are not just strings of equations, but are linked to real people, places and problems - and so have social and political origins and consequences. The ways in which complex economies, climate dynamics or disease ecologies are modelled involves deliberate approaches to creating a calculative order (Çalışkan and Callon 2009), part of a performative process of model construction. That models are always tentative and provisional should not be a surprise, but their political role must be interrogated (Morgan 2012). As several chapters in the book show, the hegemonic acceptance of particular models - whether by bankers, auditors, actuaries, corporate risk managers or early warning administrators - remains a political act, even if it is inadvertent and normalised in everyday practice.

Whether in relation to economic or financial collapse, pandemic outbreaks, regulatory responsibilities, earthquake vulnerabilities or climate catastrophe, the dilemmas are highly pressing. How then to go beyond dominant forms of political and market closure - and the ubiquitous analytical monocultures that these engender? This is particularly difficult because prevailing cultures and practices around ever-more-powerful modelling can - through the brittle hubris of their technical disciplines, performative scope and normative sincerity - actually become a core part of the problem, as deadlines are specified, limits and boundaries defined and emergencies declared (Asayama et al. 2019; Hulme 2019). 
The value of modelling must therefore be recognised as conditional and partial thus requiring attention to dialogue, deliberation and the practical politics both of conception and application (Christley et al. 2013). Models are about different ways of making sense, not definitive ways of asserting precise predictions. Beyond the narrow models that often define a predictive risk paradigm, there are of course alternative cultures of modelling (Lahsen 2005). Here plurality is central - different models tell contrasting stories, and the key for policy is the conversation between them. Models may be derived from different sources of knowledge - from high-end science to more grounded, participatory insights - and so the story must be told as part of an interactive translation between idioms and explanations.

For example, in infectious disease management, analysts may confront uncertainties emerging from process models that examine the underlying population dynamics, from pattern models that explore the spatial dimensions of disease and from participatory models rooted in local people's perspectives, as differentiated by class, age and gender. Only by developing a narrative across all three can a more integrated and effective perspective on disease control emerge (Scoones et al. 2017). Similarly, understandings of uncertainties around climate change that are obtained 'from above' - from global circulation models, for example - and 'from below' - such as from those living in flood-prone cities - can encourage a conversation about how to address climate change collectively (Mehta et al. 2019). The co-production of knowledge, power and social order (Jasanoff 2004) generates a politics of engagement that is more suited to conditions of uncertainty (Mehta and Srivastava, Chapter 7). An open epistemology is therefore called for, one that follows the well-established traditions of feminist methodology, where plural, partial, situated knowledges are central to emergent understandings and responses (Haraway 1988; Harding 1987).

In embracing uncertainty in modelling practice, the emphasis must therefore shift towards active advocacy of qualities of doubt (rather than certainty), scepticism (rather than credulity) and dissent (rather than conformity) - and so towards creative care rather than calculative control. With indeterminacy thus embraced and irreducible plurality accepted, non-control and ignorance emerge as positive values in any attempt to create narratives for policy under conditions of uncertainty.

\section{Modernities in the mirror}

Amid all this complexity, a rather straightforward lesson repeatedly asserts itself: uncertainty (of whatever kind) is by definition not a condition that is simply 'out there' in the world; uncertainty is a property of relations between what is known and who is doing the knowing. Uncertainty therefore has at least as much to do with subjective dynamics within processes of knowledge production as the supposedly objective phenomena that are being represented. Whichever view is taken of knowledge itself (from 'objective' to 'subjective'), after all, all uncertainties are always at least to some degree 'subjective' (Kahneman and Tversky 1981). Uncertainties of all kinds are therefore deeply conditioned by the contexts of the 
subjects of knowledge, and are less reflective of the external objects on which these focus. In short, with uncertainty more a mode of action than a static condition, the phenomenon of being uncertain is perhaps better understood as a relational verb than as a categorical noun (Stirling 2019a).

Why this lesson is inconvenient is that it counters the expedient idea that uncertainties are readily subject to control. And - in the everyday life of institutions around the world - it is claims to be 'in control' of uncertainty that are (as we have discussed) crucial practical political resources for arguments and commitments around modernity and progress (Stirling 2019b). Therefore, for agencies involved in world trade regimes, intergovernmental science assessments, global environmental instruments, (inter)national regulatory standards and corporate risk assessments, for instance, it is claims to be able to control uncertainty that underpin the securing of authority, justification, legitimacy, trust and wider public acceptance (Pielke 2019; Anderson and Jewell 2019). If it were admitted that key uncertainties are not under control, then the roles, identities - as well as legitimacy and authority - of these agencies would be seriously eroded, and their claimed functions of planning, prediction, management and regulation undermined.

Across different kinds of governance structure, then, efforts frequently centre on pretending that uncertainty has been subdued by a series of control measures (Katzenstein and Seybert 2108). This is done in a number of ways. First, as already discussed, many messy, complex, open-ended dimensions of uncertainty are forced into a restrictive straight-jacket of 'risk'. Here, what are held to count as the relevant parameters are simply assumed to take a very few conveniently measurable forms. Values obtained on this basis for 'probabilities' and 'magnitudes' are presumed - as a matter of faith - to take the form of single precise, scalar numbers. And the results of all these highly subjectively situated procedures (often involving various forms of modelling) are then asserted as if they were precisely fixed 'out there' in a supposedly objective world. None of these rhetorics of control are grounded in the more complex and intractable realities of uncertainty, but the resulting performance remains immune to the profound mismatch, because the pretence is so essential to organisational and political functioning.

Hinging on this fallacy of control there emerges a further significant - but often neglected - implication. Reflecting similar confusions between what is 'objective' and what is 'subjective' in the compressions of uncertainty into risk, this concerns modernity itself. For, despite the many flows of creolising diversity discussed earlier, hegemonic forms of modernity also centrally revolve around control. This has been expressed, for example, in processes of individualisation, industrialisation, capitalisation, commoditisation, rationalisation and bureaucratisation, as well as the consolidation of the nation state, the assertive hegemony around science and notions of 'democracy' and - of course - the emergence of European colonialism. All involve their own varieties of fictions, fallacies or fantasies of control (Stirling 2019c).

What is common across the institutions, practices and cultures of globalising modernity, then, is the compulsion to offer performances of control, even if these are a pretence. In this light, the pervasive experience of uncertainty is not so much telling us about the world itself: what we are seeing in anxieties about uncertainty 
across so many areas are reflections of particular versions of modernity. In this sense, the predicaments of uncertainty are modernities in the mirror.

Yet the modernist institutions of control are patently failing. The performance of 'seeing like a state' (Scott 1998) or 'enclave capital' (Ferguson 2005) is no longer convincing. Challenges to mainstream conceptions of development - and its scientific, bureaucratic and institutional underpinnings - are coming from all directions. The climate crisis, turbulence in global financial institutions, infectious diseases that spread rapidly across continents and migration between nations on a massive scale - to name but a few - all challenge the conventional order. The postWorld War II settlement that was overseen by the United Nations and the Bretton Woods institutions (the International Monetary Fund and the World Bank), and later the World Trade Organisation, all underpinned by Western science and technology, is not up to contemporary, intersecting challenges. Visions of modernity and constructions of 'development', established over the last 75 years in the West in particular, are unravelling (Hilgartner et al. 2015). Once-accepted parameters of progress - for example, permanent economic growth, an environment without limits, the provision of a welfare state, even parliamentary democracy - are being challenged (Kallis 2019; Mouffe 2018). These are of course not new observations, but it is much less recognised that the deficits of contemporary governance are intimately linked to the cumulative failings on the part of globalising modernities to face up to uncertainty in a complex, turbulent world.

In the face of such challenges, new versions of modernity are in the making. The implications of uncertainty are so profound that they challenge existing hegemonic frameworks and institutions, and drive imaginations of a post-capitalist, sustainable future, rooted in a new politics (Mason 2016; Gibson-Graham 2008). Some may reach out to utopian futures (Levitas 2013) in order to prefigure alternatives and define a new 'common sense', aimed at overturning existing hegemonic forces (Mason 2019). Others may focus on the many experiments in alternative economies, technology prototyping, architecture and design, based on the principles of the commons, community, conviviality and collectivity. While these rarely explicitly emphasise responses to conditions of uncertainty, they certainly reject the dominant modes of control, encouraging creative responses that are rooted in place (Braybrooke and Smith 2018). In turn, through attempting to decolonise the future, a prefigurative politics is imagined (Feola 2019), which defines how a world that embraced uncertainty might look. In The Way of Ignorance, the novelist, poet and farmer Wendell Berry (2008: ix-x) makes the case for such an approach:

Because ignorance is ... a part of our creaturely definition, we need an appropriate way: a way of ignorance, which is the way of neighborly love, kindness, caution, care, appropriate scale, thrift, good work, right livelihood ... The way of ignorance, therefore, is to be careful, to know the limits and the efficacy of our knowledge. It is to be humble and to work on an appropriate scale.

As Brian Wynne elaborates, ${ }^{4}$ to embrace ignorance is to celebrate the pervasive presence of 'the epistemic other' - affirming that there is always space for different 
ways of knowing any object, no matter how familiar. Surprise is thus not a threat to identity, status or authority, but a source of enriching, unrealised epistemic pluralities. But, rather than nurturing Berry's positive 'way of neighborly love', reactions can instead emphasise existential threats to a supposed 'natural other', resulting in sometimes brutal reinforcements of control. The challenge then lies in reframing ignorance as an invitation to plural hopes, and respectful recognition of difference, rather than singular fears.

However, as several chapters in the book point out, this more positive vision of the potential of alternative modernities is not without its own challenges. While abandoning the pretence of control can open up space for progressive alternatives, this too can itself also create opportunities for more regressive forces to exploit spaces of uncertainty. Without deliberate efforts at fundamental reinvention of economy, society and politics - in diverse forms, in different contexts - older, regressive tropes and practices can re-emerge. Insecurities and vulnerabilities generated by uncertainties can create a politics of fear and blame (Linke and Smith 2009). Epistemic diversity and a lack of understanding between different races and ethnic groups result in xenophobic exclusions of migrants and fortress mentalities. This entrenches borders, with further erosions of appreciations for diversity resulting in racist attacks and discrimination based on sexualities and identities. Struggles between caring hopes and controlling fears are turbulent.

For across the world today, these political spaces are being encroached on by many forms of populist, nationalist discourse, steeped in authoritarianism and violence - promising reassertions of control in the face of uncertainty (Mudde and Kaltwasser 2018; Scoones et al. 2018). ${ }^{5}$ The perceived chaos and lack of control that results from the collapse of the mainstream institutions of modernity are therefore breeding grounds for hate and violence and impositions of authoritarian rule. They also open up opportunities for exploitation and profit, in an unregulated, chaos-infused capitalism. Those with privileged positions in structures of appropriation - from national political-military elites to hedge fund managers to land speculators - can make money and gain power from capitalising on expanding conditions of uncertainty.

Across the chapters in this book, we explore how to foster the possibilities of alternative, emancipatory futures, while recognising the perils of embracing uncertainty. We argue that, in a complex, interconnected world, uncertainties are central to our common futures - and to normative ideas of sustainability and development. Through looking in the mirror, we have learned that a globalising, modernist framing of progress will not work, and has failed fundamentally. But how to usher in a more caring, collective, convivial, emancipatory alternative, without opening up to the clear, and sometimes present, dangers?

\section{Uncertainty, vulnerability and precarity}

This challenge is especially acute in contexts where people are living in highly vulnerable, uncertain settings. Here, people are necessarily focused on local, immediate, 
time-dependent life/body challenges, not the long-term future. Vernacular, grounded, everyday uncertainties reflect class, race, age, gender and other dimensions of difference. Therefore, addressing uncertainty means confronting inequality, vulnerability, precarity and the deeply embedded inheritances of history head-on. Uncertainty is never just a technical issue.

As has long been known, there is no such thing as a 'natural' hazard: hazards, and the vulnerabilities arising, are always co-constituted with social, ecological, political and economic contexts (Watts 2015; Blaikie et al. 1994). Uncertainties therefore generate place-based political ecologies and economies of vulnerability, raising questions of causal explanation and ethical responsibility (Ribot 2014). For example, the experience of flooding in the outer suburbs of New York City is unavoidably entwined with issues of poverty, housing quality and racial dislocation (Maantay and Maroko 2009). How people approach flood insurance is therefore refracted through these positionalities (Elliot 2018). In the same way, climate change in coastal Bangladesh is very real for those experiencing repeated flooding, yet externally-driven 'adaptation' responses may facilitate dispossession through the creation of alternative, 'modern' livelihoods (Paprocki 2018). The cyclone that struck Mozambique and Zimbabwe in 2019 was one of the most severe on record, but, again, its consequences have to be read politically, just as with Hurricane Katrina, which devastated parts of New Orleans in 2005 (Braun and McCarthy 2005).

Vernacular understandings of those confronting uncertainties and disasters must be the starting point for any analysis (Wynne 1996). For example, as in Mozambique in 2019, the complex effects of a flood - on housing, farming, health, mobility - are often poorly understood by humanitarian agencies and those providing protection (Hope 2019). The logics of local practice are complex, informed by diverse framings of what the risk is and to whom. Thus, in the context of the response to Ebola in West Africa, it was the local people who turned around the epidemic, linked to their located understanding of who was infected and how the disease spread. Interventions in burial ceremonies and movements to markets and between villages were key (Richards 2016). In the case of New York City, residents of the poor, outer suburbs - mostly non-white - reflected not on a technical hazard, nor on uncertainty per se, but on 'trouble': a summing up of the challenges of livelihoods linked to debt, poor housing, homelessness, disenfranchisement and lack of faith in the state (Elliot 2018).

Such practical logics and vernacular understandings emerge from place-based experience, as well as histories. People in rural Mozambique, just as suburban New York City, know they are largely on their own. The measures designed to help are palliative and limited. People must therefore respond in ways that are rooted in networked solidarities that get them through a crisis. This draws on deep associations - of religious, racial and ethnic connection - often wrapped up with longer histories and memories. Identity and place are thus inevitably entwined with how responses to uncertainty emerge. For those marginalised in relation to race, for example, people may draw on deep memories of slavery and colonialism where, on the slave ship or in the plantation or in settings subject to colonial rule, 
ancestors had suffered other uncertainties that resonate with today's experiences (McKittrick 2011). The 'slow violence' of sustained exploitation and recurrent uncertainty (Nixon 2011) contrasts dramatically with a liberal, 'white' vision of open-ended, imagined futures - a luxury created in many respects on the back of sustained exploitation (Anderson et al. 2019; Anderson 2012). In thinking about the constructions of and responses to uncertainty, particularly in contexts with long histories of marginalisation and structural inequality, the framing of ethical choice, issues of temporality and what constitutes the future for whom become critical considerations.

Yet the contemporary institutional paraphernalia of disaster intervention strategies around emergency response, preparedness planning, early warning, civil contingency, disaster risk reduction and so on, frequently fails to take such contexts into account (MacGregor et al., Chapter 8). The risk is tangible, the response is specific and a veritable industry is mobilised around it. The burgeoning institutionalisation of the disaster industry - from the global Sendai framework to local municipal contingency plans - act too often to construct narrow, manageable, technical responses (Cannon and Müller-Mahn 2010; Pelling et al., Chapter 9). Global infectious disease responses, for example, are often medicalised (focusing on a single pathogen, linked to a drugs and vaccine response) and frequently securitised (urging control at source, militarised emergency planning and draconian intervention if needed) (Lakoff 2017; Elbe 2010; MacGregor et al., Chapter 8).

The narratives of 'crisis' and 'emergency' encourage urgency and help mobilise funds, but may act to divert attention from the local and particular, where responses in different forms are being constructed. Emergencies are declared in order that normal democratic rules do not apply, bureaucratic hurdles are jumped and a securitised, post-political technocratic order is imposed (Calhoun 2010). However, the language of crisis can blind those involved to the uncertainties at play, no matter what the urgency. In the complex of responses around disasters and emergencies - from climate change (Mehta and Srivastava, Chapter 7) to disease outbreaks (MacGregor et al., Chapter 8) to terrorism (Carrapico et al., Chapter 11) - a set of technologies and practices act to govern the future.

This style of 'biopolitical' governmentality (Lentzos and Rose 2009) creates forms of control, exerted through a complex of discourse and practice. This in turn results in subjectification of key actors as victims and the reification of particular forms of technical expertise, sometimes resulting in securitised responses. Thus, the uncertainties around, say, biodiversity loss and extinction rates have been fuelling forms of 'militarised conservation' in response to 'emergency' conditions (Duffy et al. 2019). In this and other cases, intersecting modalities of emergency response in turn generate new uncertainties and inequalities, sometimes perpetuating the problem (Samimian-Darash and Rabinow 2015). As the chapters in this book show, such styles of expert-led, technocratic, securitised response are problematic, both practically and politically.

Take infectious disease control responses. From Ebola to avian influenza to COVID-19, a range of agencies have taken on responsibility for disease control within 
global health bureaucracies. Yet too often, risk is again instrumentalised, resulting in medicalised, securitised responses. This cannot address more complex disease ecologies, or how ill-health is generated through multiple, interacting factors, such as malnutrition, immunodeficiency and marginalisation. Ill-health often emerges from structural inequalities (Farmer 1996), and is lived with, and experienced, by those exposed, generating often quite individualised emotions and bodily responses (Nguyen and Peschard 2003). In such cases, knowledge about outcomes is complex and indeterminate, and so not amenable to a conventional risk response. Instead, responses must be assembled locally by multiple actors (more than singular authorities), be constituted in social relations (more than categories of institutions), be rooted in context (more than universal standards) and deploy practical knowledges from diverse sources (more than elite disciplinary expertise). Effective responses to uncertainties around ill-health are therefore emergent, based on contestation and deliberation, and grounded in everyday practical and emotional experience (MacGregor et al. Chapter 8).

However, we must ask: can those living with ill-health or confronting climate change or disasters devote the time and energy to assemble responses in the face of such bewildering, overwhelming uncertainty? Being income- and time-poor, the marginalised are often the last to engage with inclusive, deliberative processes, even if these are offered. Living in conditions of precarity means people do not have the luxury of responding to unknown futures: daily survival is the focus, and stress, anxiety and trauma are common. In such circumstances, time becomes compressed, and it is impossible to contemplate long-term future horizons. It is perhaps such people who most require state protections that are informed by expert judgement. Does passing on the responsibility for managing uncertainties to those experiencing already precarious lives only add to their burden? Who can they trust and rely on to care for their welfare?

Forms of local collective action and mutualism through traditional kin networks, religious congregations, charities, friendly societies or other collectivities have long provided this function, combined with various forms of coping, making-do and improvised resourcefulness. ${ }^{6}$ Modern welfare states took this over but have been ravaged by the hollowing out of state functions through neoliberal policies. Meanwhile, social and disaster insurance has recently become a preferred solution, addressing welfare at a distance through the market. Yet none of these models - whether through voluntary association, the state or the market - can easily address the radical uncertainties that people face. Instead, a consideration of uncertainty under conditions of precarity requires a radical rethink of notions of welfare and livelihood support.

As several chapters in this book argue, this suggests the need for a more sensitive, co-produced response that does not impose a technocratic, standardised plan, but at the same time does not load responsibilities wholly onto local people to work out on their own. For example, can insurance approaches be refashioned such that local forms of moral economy and mutual help become supported, rather than side-lined by technocratic, top-down approaches (Johnson, Chapter 3)? Such approaches must encourage 'communities of fate' - those confronting the same uncertainties with the same degree of challenge rooted in historical marginalisation 
(Marske 1991) - to come together around shared solidarities and mobilise around demanding new terms, and different approaches to insurance provision and welfare support (Elliot 2018).

Alongside welfare and livelihood support, a focus on uncertainty also requires us to re-imagine the institutions surrounding preparedness planning, contingency measures and early warning systems. As discussed above, expert-led, technocratic impositions premised on risk do not work. But what might? Can an inclusive early warning system for, say, drought or disease outbreaks be imagined, where burdens are shared, multiple knowledges brought together, networks of trust built and negotiation around interpretations facilitated? Could this be based around an improvised, experimental approach across sites, but linked to and informed by climate data, disease monitoring or disaster/hazard mapping? As Chapters 7 and 8 show, knowledge intermediaries and brokers become crucial for such initiatives, facilitating deliberation and negotiation, and offsetting rumour, speculation and concealment, which often result in expert-led systems being rejected. Who such intermediaries are would depend on the context, but trust across social differences and hierarchies is essential. Such an approach would move beyond assignations of risk and cultures of blame to a common, shared goal of navigating uncertainty together.

In sum, a new politics of uncertainty must challenge the biopolitical framings and governmentalities of conventional technocratic approaches that define populations or geographic areas as 'at risk'. Instead, the intersections of uncertainty, vulnerability, precarity and marginalisation must be taken seriously, alongside a commitment to 'cognitive justice' (Visvanathan 2005). This suggests a very different type of approach, centred on shared understandings, negotiation of outcomes and collective solidarity and mobilisation. It must be rooted in what we have earlier identified as a politics of care and conviviality, rejecting a simple reliance on state protection, standardised welfare and market-based insurance.

Asking questions about whose crisis, catastrophe or emergency it is, and how it is experienced, is not a denial of the importance of the event, or the roles for expertise in defining key aspects. Instead, it is a recognition that climate change, disease, earthquakes - or other uncertain events - will look different from the standpoint of those living in conditions of precarity and vulnerability. This means recasting responses, moving away from ones that are forged through externallyimposed, expert-led governmentality towards forms of 'response-ability' (Haraway 1997), with located capabilities and horizontal accountabilities at the core. As we discuss further in the next section, this has profound implications, including a need to reject all kinds of authoritarian control - technocratic as much as autocratic - in order to foster opportunities for more caring forms of political relations and action under conditions of uncertainty.

\section{Uncertainty and the politics of responsibility}

Uncertainties create cultures of blame, but also a politics of responsibility and accountability. Who is in charge? Who owns what risk? Who is responsible for 
mitigation? Where does epistemic, cognitive justice lie? The rise of a marketised form of risk governmentality, typified by the promotion of various forms of insurance (Johnson, Chapter 3), has generated a particular style of politics, where risks are redistributed through market mechanisms. These approaches often overshadow other approaches to the redistribution of risk and the allocation of responsibility.

In particular, the less obvious forms of social solidarity and mutualism, based on collective forms of protection against risk and uncertainty, are too often ignored. But, if uncertainties are indeterminate and non-knowledge is central, then ways of life are simply not insurable in any conventional sense, and alternative, 'moral economy' responses are required. As a result, very different types of governance must emerge, associated with new roles for citizens confronting uncertainty. To respond to complex uncertainties, citizens cannot just be customers of standardised insurance products, nor passive citizens of supposedly benevolent technocratic states they must take on new roles, as part of collectivities that are based on the principle of solidarity, where care and collaboration are central (Bollier and Helfrich 2014; Gibson-Graham 2008).

If openness is encouraged, challenges will necessarily arise around 'regulatory arbitrage' - deciding which version counts in commitments to negotiated outcomes. We must ask: who is the bearer of risk and uncertainty of last resort, and what is the role of the state in the context of a less hierarchical, more citizen-led approach to governance? Responsibilities must be shared, fostering horizontal and vertical accountabilities as embedded politically vibrant relationships, not as part of simple auditable accounting (Gaventa 2002). And such relationships need to be sustained over time, since the addressing of one source of uncertainty inevitably raises new ones. Processes must be continuous and recursive, based on experimentation, learning, evaluation and adaptation (Guijt 2019). This requires new styles of expertise, legal mediation and state regulation that are more flexible and open, requiring a radical reconfiguration of professional and institutional approaches in planning and regulation (van Zwanenberg, Chapter 4; Kaker et al., Chapter 6).

The sort of deliberative, adaptive, experimental forms of governance that accepting uncertainty demands already happen, of course - but often without recognition. So, for example, in relation to the governance of energy infrastructure in Europe, experiments have taken place around the transport and supply of electricity, allowed for by the European Union's decentralised policy regime, and guided by the principle of subsidiarity (Rangoni 2019). Learning among companies and regulators has taken place, and substantial shifts have occurred in regimes over time, without directed intervention. Similarly, in complex, dispersed supply chains for high-tech manufacturing, where networks spread across the world between large and small companies, collaborative negotiations around contracts occur incrementally. No one player is in a position to impose, and the technological and market conditions are highly uncertain, but cooperation is essential if the products are to be delivered (Dodgson 2018). This is not just ad hoc 'muddling through' (Lindblom 1959), but a form of networked collective action based on inclusion, conversation and collaboration. 
These 'new commons', frequently facilitated by easy digital connection, allow for a whole range of collaborative approaches to inclusive innovation and shared economic activity - from hacker and maker spaces to urban gardening and food sovereignty to community energy supply systems to urban development in 'transition towns' (Kirwan et al. 2016). In different ways, these create both a new form of community-based wealth-building, but also - crucially - a different route to addressing uncertainty through a more collective, shared approach. A key feature of all these initiatives - from global technology supply chains to small community gardens - is the movement towards an expected norm of permanent adaptability, as part of a process shared within a collective or network. Thus, equality and democracy - locally and across networks - become intrinsic to addressing uncertainties (Rayner and Cantor 1987).

Debates about the governance of risk and uncertainty must therefore go beyond the rigidities of the allocation and distribution of responsibility through insurance liability, legal claims or regulatory fiat, and move to a more open, co-produced, negotiated approach, where relationships and trust are central. Some profound challenges are presented to discourses on trust itself. By contrast to conventional emphases on relations of trust flowing up power gradients (from those who are governed to those doing the governing), trust becomes recognisable as an intrinsically reciprocal and symmetrical social process (Stirling 2015). And, of course, the political implications here concern not just relations within structures, but the constituting of such structures themselves. In moving beyond cultures of control to ones of care and conviviality, hierarchy, inequality and appropriation are seen as problematic as the modes of calculation, standardisation and aggregation discussed earlier.

As we have already observed, this creates a momentum for a fundamental rethinking of existing relationships between state protection, technical expertise and deliberative citizenship under uncertainty. And this, in turn, requires a newly pluralised, inclusive politics of responsibility, where states, corporations, legal systems and science all have different, new roles. In moving from control to care and conviviality, the only meaningful ways to achieve robustness and reconciliation in the face of burgeoning uncertainties involve justice, equality and plurality.

\section{Rethinking the politics of uncertainty: the challenges of transformation}

As we have seen, uncertainties can create fear, anxiety and closure, and can be linked to the rise of regressive, authoritarian populisms, profit- and rent-seeking capital and capture by elites. But uncertainties can also generate hope, creativity, curiosity, entrepreneurship, discovery, innovation and epistemic humility - and so possibilities for emancipatory democratic transformation. Diverse questions therefore emerge around facilitating these progressive transformations. What methods, processes and mobilisations can tilt the balance towards more positive outcomes? How can alternatives be prefigured to reinforce this new politics? Who is centred 
in transformatory spaces, and who is to the side? And what solidarities, ethics and styles of reflexivity are required for this new politics of uncertainty?

It is in relation to such questions that the balance between control and care/ conviviality comes to the fore. As we have suggested, open discussion of contrasts between risk and uncertainty can profoundly challenge the failures, fallacies and fictions of control. By interrogating what uncertainties are - and how we understand, feel and respond to them - we can both help to destabilise, but also rebalance and reinvent, the institutions and practices of globalising modernity. This helps resist the 'closing down' effects of individualisation, commodification, financialisation, bureaucratisation, audit and securitisation. And beyond this deconstruction, this book attempts a reflection on the politics of uncertainty across different areas of political life - highlighting both possibilities and limits for the opening up of new forms of transformation.

Again, uncertainties can be generative of diverse, imagined alternatives. By opening up spaces to re-imagine futures, to dream and to construct alternatives, uncertainties can be confronted in positive ways: not as threats or sources of fear, but as sources of hope and possibility. As Rebecca Solnit (2016: xii) argues:

Hope locates itself in the premises that we don't know what will happen and that in the spaciousness of uncertainty is room to act. When you recognize uncertainty, you recognize that you may be able to influence the outcomes you alone or you in concert with a few dozen or several million others. Hope is an embrace of the unknown and knowable, an alternative to the certainty of both optimists and pessimists.

As she says, this requires a mobilisation of future-making among different actors. Eschewing grand visions and stylised expert scenarios, these unofficial futures emerge in intersecting uncertainties from the ground up, in everyday, 'quotidian utopias of experience' (Mahony and Beck 2019). In relation to climate change, this is perhaps already happening through the arguments of the youth climate strikers addressing 'system change' not just climate change, or the demand from Extinction Rebellion for 'citizens' assemblies' to deliberate on alternatives (Bain and Bongiorno 2019). While often framed problematically in sometimes authoritarian and controlling terms of 'urgent action' and 'impending emergency', and with frequently misplaced deference to narrow forms of expert science and singular targets (Asayama et al. 2019), these mobilisations can nevertheless help to open up spaces that demonstrate, explore and experiment with alternatives.

It is essential to bring into these conversations, the diverse implications of uncertainty. One recurrent theme running through this book is that open and accountable engagements with the politics of uncertainty are more imperative now than ever. For it is through such politics that the mainstream science and institutions of climate change must grapple with issues such as intergenerational justice and alternative perspectives on 'limits' or 'growth' (Kallis 2019), and so challenge the standard integrated assessment models that have guided the work of the International Panel 
on Climate Change and others to date (Beck and Mahony 2017). All this requires uncertain futures to be central to debates about climate change, environmental justice and sustainability.

Yet we must recognise that the socio-technical imaginaries that guide policy and politics are deeply resistant to change (Jasanoff and Kim 2015). Policy narratives routinely get stuck because they serve professional and institutional interests, and become convenient myths that are taken for granted (Keeley and Scoones 2003). Disrupting the comfortable status quo and confronting incumbent privilege and hegemonic power can be difficult. Mobilisations, such as those we are seeing around climate change, are important, but must extend across domains, as the chapters that follow argue. As with climate change, rethinking migration policy, city planning, infectious disease responses, critical infrastructure design, the regulation of technology, and finance and banking practice, among others, is hugely challenging, given the power and authority of incumbent regimes. The argument of this book is that appreciations of uncertainty provide the golden thread that connects these issues. Given the consistent failures of mainstream modernist, technocratic institutions, it is vital to embed the imagining of transformative change in a vibrant politics of uncertainty.

This is not going to happen by itself. The lesson of the emergent, networked climate movement - as with others around food sovereignty, housing and land rights, energy poverty or commoning approaches - is that new solidarities are essential. Confronting uncertainty becomes central; not as separate and additional to resistance to inequality, injustice and poverty, but as simultaneous and inseparable from it. This requires imagining very different futures that challenge deeply entrenched power and authority. In forging progressive alliances for re-imagining the future, the potential exclusions of both knowledges and people must be acknowledged, as we have discussed. Who has the luxury to create such alternatives? Whose jobs and livelihoods are threatened by alternative pathways? How can contingent privileges be harnessed to flatten encompassing gradients of power that restrict inclusion?

For many living precarious lives, uncertainties that threaten existence on a daily basis are created through histories of oppression and marginalisation. While the uncertainties of climate change may be affecting us all, the fossil fuel dependency of the global economy only emerged through unequal patterns of development linked to historical processes of exploitation. Those digging coal in hazardous working conditions, perhaps in the global South, are also facing uncertainties of a more immediate kind. The debate about uncertainty and transformations to sustainability therefore must create forms of solidarity and alternative pathways that appreciate longer histories in the politics of uncertainty.

All this involves actively supporting alternatives emerging in experimentation and action, especially in marginalised settings. And, in this way, these new politics of uncertainty chime with the long-standing politics of emancipation and decolonisation. For the resulting transformative aspirations are essentially the same: in moving from institutions of control to cultures of care and conviviality, familiar values come to the fore - of equality, solidarity, collectivity and mutuality. Each draws on moral 
economies of hope, rather than fear. And it is through embracing uncertainties in their many forms - and challenging the pervasive kinds of controlling apparatus that work to deny and obscure them - that a positive, progressive potential emerges at a time of crisis for democratic struggle. Now is therefore the moment for such pluralised, diversified, distributed and egalitarian processes of action and transformation. Just as knowledges are co-produced with social orders, so may the more explicit embracing of uncertainties help to open up recalcitrant political structures and decolonise our unfolding futures.

\section{Notes}

1 The global COVID-19 pandemic was unfolding as this book went to press. Whilst this chapter therefore does not address this issue directly, the discussion is nonetheless relevant throughout.

2 See comments by Dipak Gyawali at The Politics of Uncertainty symposium, July 2019, www. buff.ly/35D5RSI (accessed, 7 February 2020).

3 See podcast, 'Youth Transformations and Global Warming', November 2019, www. transformineducation.org/podcasts/youth-transformations-global-warming (accessed 7 February 2020).

4 In comments by Brian Wynne at The Politics of Uncertainty symposium, July 2019, and elaborated in subsequent very helpful personal communications.

5 See materials from the Emancipatory Rural Politics Initiative, www.opendemocracy.net/ en/authoritarian-populism-and-rural-world/ (accessed 7 February 2020).

6 In the Democratic Republic of Congo this is referred to as 'débrouillardise', which is seen as a national trait that is vital for survival under conditions of war and economic collapse (Jourdan 2013).

\section{References}

Adam, B., Beck, U. and Van Loon, J. (eds) (2000) The Risk Society and Beyond: Critical Issues for Social Theory, London: Sage

Ahuja, R. (2009) Pathways of Empire: Circulation, 'Public Works' and Social Space in Colonial Orissa, c. 17801914 (New Perspectives in South Asian History), Hyderabad: Orient Black Swan

Amoore, L. (2013) The Politics of Possibility: Risk and Security Beyond Probability, Durham NC and London: Duke University Press

Anderson, B. (2012) 'Preemption, Precaution, Preparedness: Anticipatory Action and Future Geographies', Progress in Human Geography 34.6: 777-798

Anderson, B., Grove, K., Rickards, L. and Kearnes, M. (2019) 'Slow Emergencies: Temporality and the Racialized Biopolitics of Emergency Governance', Progress in Human Geography, May 2019, DOI: 10.1177/0309 132519849263

Anderson, K. and Jewell, J. (2019) 'Debating the Bedrock of Climate-Change Mitigation Scenarios', Nature, 16 September 2019, www.nature.com/articles/d41586-019-02744-9 (accessed 25 October 2019)

Appadurai, A. (ed) (1988) The Social Life of Things: Commodities in Cultural Perspective, Cambridge: Cambridge University Press

Arora, S. (2019) 'Admitting Uncertainty, Transforming Engagement: Towards Caring Practices for Sustainability Beyond Climate Change', Regional Environmental Change 19.6: 1571-1584 
Arora, S. and Glover, D. (2017) Power in Practice: Insights from Technography and Actor-Network Theory for Agricultural Sustainability, STEPS Working Paper 100, Brighton: STEPS Centre

Asayama, S., Bellamy, R., Geden, O., Pearce,W. and Hulme, M. (2019) 'Why Setting a Climate Deadline is Dangerous', Nature Climate Change 9.8: 570-572

Bain, P.G. and Bongiorno, R. (2019) 'It's Not Too Late to do the Right Thing: Moral Motivations for Climate Change Action', Wiley Interdisciplinary Reviews: Climate Change 11: 615

Barthe, Y., Callon, M. and Lascoumes, P. (2009) Acting in an Uncertain World: An Essay on Technical Democracy, Cambridge MA: MIT Press

Beck, S. and Mahony, M. (2017) 'The IPCC and the Politics of Anticipation' Nature Climate Change 7: 311-313

Beck, U. (1992) Risk Society: Towards a New Modernity, London: Sage

Beck, U., Giddens, A. and Lash, S. (1994) Reflexive Modernization: Politics, Tradition and Aesthetics in the Modern Social Order, Stanford CA: Stanford University Press

Beckert, J. and Bronk, R. (eds) (2018) Uncertain Futures: Imaginaries, Narratives and Calculation in the Economy, Oxford: Oxford University Press

Berry, W. (2008) 'The Way of Ignorance', in W. Jackson and B. Vitek (eds) The Virtues of Ignorance: Complexity, Sustainability, and the Limits of Knowledge, Kentucky: The University Press of Kentucky

Blaikie, P., Cannon, T., Davis, I. and Wisner, B. (eds) (1994) At Risk: Natural Hazards, People's Vulnerability and Disasters, London: Routledge

Bollier, D. and Helfrich, S. (eds) (2014) The Wealth of the Commons: A World Beyond Market and State, Amhurst: Levellers Press

Braun, B. and McCarthy, J. (2005) 'Hurricane Katrina and Abandoned Being', Environmental and Planning D: Society and Space 23.6: 802-809

Braybrooke, K. and Smith, A. (2018) 'Introduction: Liberatory Technologies for Whom? Exploring a New Generation of Makerspaces Defined by Institutional Encounters', Journal of Peer Production 2.12: 1-13

Bronk, R. (2019) 'Uncertain Futures and the Politics of Uncertainty', STEPS Centre Blog, 3 September 2019, https://steps-centre.org/blog/uncertain-futures-and-the-politics-ofuncertainty/ (accessed 7 February 2020)

Bronk, R. and Jacoby, W. (2016) Uncertainty and the Dangers of Monocultures in Regulation, Analysis, and Practice, MPIFG Discussion Paper 16/6, Cologne: Max Planck Institute for Studying Societies

Calhoun, C. (2010) 'The Idea of Emergency: Humanitarian Action and Global (Dis)order', in D. Fassin and M. Pandolfi (eds) Contemporary States of Emergency: the Politics of Military and Humanitarian Interventions, New York: Zone Books

Çalışkan, K. and Callon, M. (2009) 'Economization, Part 1: Shifting Attention from the Economy Towards Processes of Economization', Economy and Society 38.3: 69-398

Cannon, T. and Müller-Mahn, D. (2010) 'Vulnerability, Resilience and Development Discourses in Context of Climate Change', Natural Hazards 55.3: 621-635

Caplan, P. (ed) (2000) Risk Revisited, London: Pluto Press

Christley, R.M., Mort, M., Wynne, B., Wastling, J.M., Heathwaite, A.L., Pickup, R., Austin, Z. and Latham, S.M. (2013) "“Wrong, but Useful”: Negotiating Uncertainty in Infectious Disease Modelling', PLOS One 8.10e76277

Cowen, M. and Shenton, D. (1996) Doctrines of Development, London: Routledge

Csordas, T.J. and Harwood, A. (eds) (1994) Embodiment and Experience: The Existential Ground of Culture and Self, Cambridge: Cambridge University Press

Curran, D. (2018) 'Beck's Creative Challenge to Class Analysis: From the Rejection of Class to the Discovery of Risk-Class', Journal of Risk Research 21.1: 29-40 
Da Col, G. and Humphrey, C. (2012) 'Introduction: Subjects of Luck-Contingency, Morality, and the Anticipation of Everyday Life', Social Analysis 56.2: 1-25

Dillon, M. (2007) 'Governing through Contingency: the Security of Biopolitical Governance', Political Geography 26.1: 41-47

Dodgson, M. (2018) Technological Collaboration in Industry: Strategy, Policy and Internationalization in Innovation, London: Routledge

Douglas, M. (1986) Risk Acceptability According to the Social Sciences, New York: Russell Sage Foundation

Driebe, D. and McDaniel, R.R. (2005) 'Complexity, Uncertainty and Surprise: An Integrated View', in R.R. McDaniel and D.J. Driebe (eds) Uncertainty and Surprise in Complex Systems, Berlin and Heidelberg: Springer

Dryzek, J.S. (2012) Foundations and Frontiers of Deliberative Governance, Oxford: Oxford University Press

Duffy, R., Massé, F., Smidt, E., Marijnen, E., Büscher, B., Verweijen, J., Ramutsindela, M., Simlai, T., Joanny, L. and Lunstrum, E. (2019) 'Why We Must Question the Militarisation of Conservation', Biological Conservation 232: 66-73

Elbe, S. (2010) Security and Global Health, Cambridge: Polity

Elliott, R. (2018) “"Scarier than Another Storm": Values at Risk in the Mapping and Insuring of US Floodplains', The British Journal of Sociology 70.3: 1067-1090

Evans, J., Karvonen, A. and Raven, R. (eds) (2016) The Experimental City, London: Routledge

Ewald, F. (1991) 'Insurance and Risk', in G. Burchell, C. Gordon and P. Miller (eds) The Foucault Effect: Studies in Governmentality, Chicago: Chicago University Press

Farmer, P. (1996) 'On Suffering and Structural Violence: A View from Below', Daedalus 125.1: $261-283$

Fenton-O'Creevy, M. (2019) Solidarity, Insurance, Emotions and Uncertainty, STEPS Centre blog, 19 September https://steps-centre.org/blog/solidarity-insurance-emotions-anduncertainty/ (accessed 7 February 2020)

Feola, G. (2019) 'Degrowth and the Unmaking of Capitalism Beyond "Decolonization of the Imaginary”, ACME: An International Journal for Critical Geographies 18.4: 977-997

Ferguson, J. (2005) 'Seeing like an Oil Company: Space, Security, and Global Capital in Neoliberal Africa', American Anthropologist 107.3: 377-382

Folbre, N., Olin Wright, E., Andersson, J., Hearn, J., Himmelweit, S. and Sterling, A. (2018) 'The Multiple Directions of Social Progress: Ways Forward', in International Panel on Social Progress (ed) Rethinking Society for the 21st Century: Report of the International Panel on Social Progress, Cambridge: Cambridge University Press

Funtowicz, S.O. and Ravetz, J.R. (1990) Uncertainty and Quality in Science for Policy, New York: Springer

Gaonkar, D.P. (1999) ‘On Alternative Modernities', Public Culture 11.1: 1-18

Gaventa, J. (2002) 'Exploring Citizenship, Participation and Accountability', IDS Bulletin 33.2: 1

Gibson-Graham, J.K. (2008) 'Diverse Economies: Performative Practices for Other Worlds', Progress in Human Geography 32.5: 613-632

Grabel, I. (2017) When Things Don't Fall Apart: Global Financial Governance and Developmental Finance in an Age of Productive Incoherence, Cambridge, MA: MIT Press

Guijt, I. (2019) 'How Can NGOs Feel at Home with Uncertainty?', STEPS Centre blog, 19 November, https://steps-centre.org/blog/how-can-ngos-feel-at-home-withuncertainty/ (accessed 7 February 2020)

Haldane, A. (2010) 'The $\$ 100$ Billion Question', available at: www.bankofengland. co.uk/speech/2010/the-100-billion-question-speech-by-andy-haldane (accessed 7 February 2020) 
- (2009) 'Rethinking the Financial Network', available at: www.bankofengland.co.uk/ speech/2009/rethinking-the-financial-network (accessed 7 February 2020)

Haraway, D. (1988) 'Situated Knowledges: The Science Question in Feminism and the Privilege of Partial Perspective', Feminist Studies 14.3: 575-599

Haraway, D. (1997) Modest_Witness@,Second_Millennium.FemaleMan_Meets_OncoMouse: Feminism and Technoscience, London: Routledge

Harcourt, W. (2013) Body Politics in Development: Critical Debates in Gender and Development, London: Zed Books

Harding, S.G. (1987) Feminism and Methodology: Social Science Issues, Bloomington: Indiana University Press

Hastrup,K. and Skrydstrup,M.(eds) (2013) The Social Life of Climate Change Models: Anticipating Nature, London: Routledge

Hilgartner, S., Miller, C.A. and Hagendijk, R. (eds) (2015) Science and Democracy: Making Knowledge and Making Power in the Biosciences and Beyond, London: Routledge

Hobden, S. (2002) Historical Sociology of International Relations, Cambridge: Cambridge University Press

Hope, M. (2019) 'Cyclones in Mozambique May Reveal Humanitarian Challenges of Responding to a New Climate Reality', The Lancet Planetary Health 3.8: e338-e339

Hough, S.E. (2002) Earthshaking Science: What We Know (and Don't Know) About Earthquakes, Princeton: Princeton University Press

Hulme, M. (2019) 'Climate Emergency Politics is Dangerous', Issues in Science and Technology Fall 2019, 23-25

Ibarra-Colado, E. (2006) 'Organization Studies and Epistemic Coloniality in Latin America: Thinking Otherness from the Margins', Organization 13: 463-488

Illich, I. (1973) Tools for Conviviality, New York: Harper \& Row

Jasanoff, S. (ed) (2004) States of Knowledge: The Co-Production of Science and the Social Order, London: Routledge

Jasanoff, S. and Kim, S.H. (eds) (2015) Dreamscapes of Modernity: Sociotechnical Imaginaries and the Fabrication of Power, Chicago and London: University of Chicago Press

Johnson, L. (2013) 'Index Insurance and the Articulation of Risk-Bearing Subjects', Environment and Planning $A$ 45.11: 2663-2681

Jourdan, L. (2013) 'From Humanitarian to Anthropologist: Writing at the Margins of Ethnographic Research in the Democratic Republic of Congo', in S. Thomson, A. Ansoms and J. Murison (eds) Emotional and Ethical Challenges for Field Research in Africa, London: Palgrave Macmillan

Kahneman, D. and Tversky, A. (1981) Variants of Uncertainty, Stanford: Stanford University Press

Kallis, G. (2019) Limits: Why Malthus was Wrong and Why Environmentalists Should Care, Stanford: Stanford University Press

Katzenstein, P.J. and Seybert, L.A. (eds) (2018) Protean Power: Exploring the Uncertain and Unexpected in World Politics, Cambridge: Cambridge University Press

Kaup, M. (2012) Neobaroque in the Americas: Alternative Modernities in Literature, Visual Art and Film, Charlottesville: University of Virginia Press

Kearnes, M. and Wynne, B. (2007) 'On Nanotechnology and Ambivalence: The Politics of Enthusiasm', NanoEthics 1: 131-142

Keeley, J. and Scoones, I. (2003) Understanding Environmental Policy Processes: Cases from Africa, London: Routledge

Kirwan, S., Dawney, S. and Brigstocke, J. (eds) (2016) Space, Power and the Commons: The Struggle for Alternative Futures, London: Routledge 
Kleist, N. and Thorsen, D. (eds) (2016) Hope and Uncertainty in Contemporary African Migration, London: Routledge

Knight, F.H. (1921) Risk, Uncertainty and Profit, New York: Courier Corporation

Krätli, S. and Schareika, N. (2010) 'Living off Uncertainty: The Intelligent Animal Production of Dryland Pastoralists', The European Journal of Development Research 22: 605-622

Lahsen, M (2005) 'Seductive Simulations? Uncertainty Distribution around Climate Models', Social Studies of Science 35: 895-922

Lakoff, A. (2017) Unprepared: Global Health in a Time of Emergency, Oakland: University of California Press

Leach, M. and Scoones, I. (2013) 'The Social and Political Lives of Zoonotic Disease Models: Narratives, Science and Policy', Social Science and Medicine 88: 10-17

Leach, M., Stirling,A.C. and Scoones, I. (2010) Dynamic Sustainabilities: Technology, Environment, Social Justice, London: Earthscan Routledge

Lenton, T.M., Rockström, J., Gaffney, O., Rahmstorf, S., Richardson, K., Steffen, W. and Schellnhuber, H.J. (2019) 'Climate Tipping Points—Too Risky to Bet Against', Nature 575: 592-595

Lentzos, F. and Rose, N. (2009) 'Governing Insecurity: Contingency Planning, Protection, Resilience', Economy and Society 38.2: 230-254

Levitas, R. (2013) Utopia as Method: The Imaginary Reconstitution of Society, London: Palgrave Macmillan

Lindblom, C.E. (1959) 'The Science of Muddling Through', Public Administration Review 19.2: $79-88$

Linke, U. and Smith, D.T. (eds) (2009) Cultures of Fear: A Critical Reader, London: Pluto Press Luhmann, N. (1993) Risk: A Sociological Theory, R. Barrett (trans.), New York: W. de Gruyter Maantay, J. and Maroko, A. (2009) 'Mapping Urban Risk: Flood Hazards, Race and Environmental Justice in New York', Applied Geography 29.1: 111-124

MacKenzie, D. and Spears, T. (2014) 'The Formula that Killed Wall Street': The Gaussian Copula and Modelling Practices in Investment Banking', Social Studies of Science 44.3: 393-417

Mahony, M. and Beck, S. (2019) 'Infrastructures of the Imagination: Uncertainty and the Politics of Prefiguration', STEPS Centre blog, 1 October, https://steps-centre.org/ blog/infrastructures-of-the-imagination-uncertainty-and-the-politics-of-prefiguration/ (accessed 7 February 2020)

Marske, C.E. (ed) (1991) Communities of Fate: Readings in the Social Organization of Risk, Maryland: University Press of America

Mason, P. (2019) Clear Bright Future: A Radical Defence of the Human Being, London: Penguin — (2016) Post-Capitalism: A Guide to Our Future, London: Macmillan

Mazzucato M (2018) The Value of Everything: Making and Taking in a Global Economy, London: Allen Lane

McKittrick, K. (2011) 'On Plantations, Prisons, and a Black Sense of Place', Social \& Cultural Geography 12.8: 947-963

Mehta, L., Srivastava, S., Adam, H.N., Alankar, Bose, S., Ghosh, U. and Kumar, V. (2019) "Climate Change and Uncertainty from "Above" and "Below": Perspectives from India', Regional Environmental Change 19.6: 1533-1547

Mol, A. and Law, J. (2004) 'Embodied Action, Enacted Bodies: The Example of Hypoglycaemia', Body and Society 10.2-3: 43-62

Morgan, M.S. (2012) The World in The Model: How Economists Work and Think, Cambridge: Cambridge University Press

Mouffe, C. (2018) For a Left Populism, London:Verso Books 
Mudde, C. and Rovira Kaltwasser, C. (2018) 'Studying Populism in Comparative Perspective: Reflections on the Contemporary and Future Research Agenda', Comparative Political Studies 51(13): 1667-1693

Mythen, G., Burgess, A. and Wardman, J.K. (2018) 'The Prophecy of Ulrich Beck: Signposts for the Social Sciences', Journal of Risk Research 21.1: 96-100

Nguyen, V.K. and Peschard, K. (2003) 'Anthropology, Inequality, and Disease: A Review', Annual Review of Anthropology 32.1: 447-474

Nixon, R. (2011) Slow Violence and the Environmentalism of the Poor, Cambridge MA: Harvard University Press

Nowotny, H. (2015) The Cunning of Uncertainty, Chichester: John Wiley and Sons

Paprocki, K. (2018) 'Threatening Dystopias: Development and Adaptation Regimes in Bangladesh', Annals of the American Association of Geographers 108.4: 955-973

Pielke, R. (2019) 'If Climate Scenarios Are Wrong For 2020, Can They Get 2100 Right?' Forbes Magazine, 21 October 2019, www.forbes.com/sites/rogerpielke/2019/10/21/ if-climate-scenarios-are-wrong-for-2020-can-they-get-2100-right/\#4773cf502c7f (accessed 7 February 2020)

Power, M. (2004) The Risk Management of Everything: Rethinking The Politics of Uncertainty, London: Demos

Rangoni, B. (2019) 'Architecture and Policy-Making: Comparing Experimentalist and Hierarchical Governance in EU Energy Regulation', Journal of European Public Policy 26.1: $63-82$

Raworth, K. (2017) Doughnut Economics: Seven Ways to Think like a 21st-Century Economist, Vermont: Chelsea Green Publishing

Rayner, S. and Cantor, R. (1987) 'How Fair is Safe Enough? The Cultural Approach to Societal Technology Choice', Risk Analysis 7.1: 3-9

Ribot, J. (2014) 'Cause and Response: Vulnerability and Climate in the Anthropocene', Journal of Peasant Studies 41.5: 667-705

Richards, P. (2016) Ebola: How a People's Science Helped End an Epidemic, London: Zed Books

Roe, E. (2013) Making the Most of Mess: Reliability and Policy in Today's Management Challenges, Durham NC: Duke University Press

Sabel, C.F. and Zeitlin,J. (eds) (2010) Experimentalist Governance in the European Union: Towards a New Architecture, Oxford: Oxford University Press

Samimian-Darash, L. and Rabinow, P. (eds) (2015) Modes of Uncertainty: Anthropological Cases, Chicago: University of Chicago Press

Scoones, I. (2019) What is Uncertainty and Why Does it Matter?, STEPS Working Paper 105, Brighton: STEPS Centre

- (2016) 'The Politics of Sustainability and Development', Annual Review of Environment and Resources 41: 293-319

Scoones, I., Edelman, M., Borras Jr, S.M., Hall, R., Wolford, W. and White, B. (2018) 'Emancipatory Rural Politics: Confronting Authoritarian Populism', The Journal of Peasant Studies 45.1: 1-20

Scoones, I., Jones, K., Lo Iacono, G., Redding, D.W., Wilkinson, A. and Wood, J.L.N. (2017) 'Integrative Modelling for One Health: Pattern, Process and Participation', Philosophical Transactions of the Royal Society B: Biological Sciences 372: 1725

Scoones, I., Newell, P. and Leach, M. (eds) (2015) The Politics of Green Transformations, London: Routledge

Scoones, I., Stirling, A., Abrol, D., Atela, J., Charli-Joseph, L., Eakin, H., Ely, A., Olsson, P., Pereira, L., Priya, R. and van Zwanenberg, P. (2018) Transformations to Sustainability, STEPS Working Paper 104, Brighton: STEPS Centre 
Scott, J.C. (1998) Seeing Like a State: How Certain Schemes to Improve the Human Condition Have Failed, New Haven: Yale University Press

Shove, E., Pantzar, M. and Watson, M. (2012) The Dynamics of Social Practice: Everyday Life and How it Changes, London: Sage

Skrimshire, S. (2014) 'Climate Change and Apocalyptic Faith', Wiley Interdisciplinary Reviews: Climate Change 5.2: 233-246

Solnit, R. (2016) Hope in the Dark: Untold Histories, Wild Possibilities, London: Haymarket Books

Stirling, A. (2019a) 'How Deep is Incumbency? A "Configuring Fields" Approach to Redistributing and Reorienting Power in Socio-material Change', Energy Research and Social Science 58: 101239

- (2019b) 'Engineering and Sustainability: Control and Care in Unfoldings of Modernity', in D.P. Michelfelder and N. Doorn (eds) Routledge Companion to the Philosophy of Engineering, Routledge: London

- (2019c) 'Sustainability and the Politics of Transformations: From Control to Care in Moving Beyond Modernity', in J. Meadowcroft, D. Banister, E. Holden, O. Langhelle, K. Linnerud and G. Gilpin (eds) What Next for Sustainable Development?, Cheltenham: Edward Elgar Publishing

(2015) 'Emancipating Transformations: from Controlling "the Transition" to Culturing Plural Radical Progress', in I. Scoones, M. Leach and P. Newell (eds) The Politics of Green Transformations, London: Routledge

_ (2008) " "Opening Up" and "Closing Down" Power, Participation and Pluralism in the Social Appraisal of Technology', Science, Technology and Human Values 33.2: 262-294

_ (1999) 'On "Precautionary" and "Science Based" Approaches to Risk Assessment and Environmental Appraisal', in A. Klinke, O. Renn, A. Rip, A. Salo and A. Stirling (eds) On Science and Precaution in the Management of Technological Risk. Vol. II, Case Studies, Sevilla: European Science and Technology Observatory, report EUR 19056/EN/2, European Commission Joint Research Centre

Sword-Daniels, V., Eriksen, C., Hudson-Doyle, E.E., Alaniz, R., Adler, C., Schenk, T. and Vallance, S. (2018) 'Embodied Uncertainty: Living with Complexity and Natural Hazards', Journal of Risk Research 21.3: 290-307

Taleb, N.N. (2007) The Black Swan: The Impact of the Highly Improbable, New York: Random House

Taraborrelli, A. (2015) Contemporary Cosmopolitanism, London: Bloomsbury

Taylor, N. (2019) 'Whose Risk? Whose Responsibility? The Politics and Financialisation of Uncertainty', STEPS blog, 25 September, https://steps-centre.org/blog/whoserisk-whose-responsibility-the-politics-and-financialisation-of-uncertainty/ (accessed 7 February 2020)

Thompson, M. and Gyawali, D. (2007) 'Uncertainty Revisited or the Triumph of Hype Over Experience. New Introduction', in M. Thompson, M. Warburton and T. Hatley, Uncertainty on a Himalayan Scale, Kathmandhu: Himal Press

Thompson, M. and Warburton, M. (1985) 'Uncertainty on a Himalayan Scale', Mountain Research and Development 5.2: 115-135

Thompson, M., Ellis, R. and Wildavsky, A. (1990) Cultural Theory, London: Routledge

Tompkins, E. and Adger, W.N. (2004) 'Does Adaptive Management of Natural Resources Enhance Resilience to Climate Change?', Ecology and Society 9.2: 10

Tuckett, D. (2018) 'Conviction Narrative Theory', in R. Beckert and R. Bronk (eds) Uncertain Futures: Imaginaries, Narratives, and Calculation in the Economy, Oxford: Oxford University Press 
Visvanathan, S. (2005) 'Knowledge, Justice and Democracy', in M. Leach, I. Scoones and B. Wynne (eds) Science and Citizens: Globalization and the Challenge of Engagement, London: Zed Books

Walker, W.E., Harremoës, P., Rotmans, J., van der Sluijs, J.P., van Asselt, M.B.A., Janssen, P. and Krayer von Krauss, M.P. (2003) 'Defining Uncertainty: A Conceptual Basis for Uncertainty Management in Model-Based Decision Support', Integrated Assessment 4.1: $5-17$

Wansleben, L. (2014) 'Consistent Forecasting vs. Anchoring of Market Stories: Two Cultures of Modeling and Model Use in a Bank', Science in Context 27.4: 605-630

Watts, M. (2015) 'Now and Then: The Origins of Political Ecology and the Rebirth of Adaptation as a Form of Thought', in T. Perreault, G. Bridge and J. McCarthy (eds) The Routledge Handbook of Political Ecology, London: Routledge

Watts, M.J. and Bohle, H.G. (1993) 'The Space of Vulnerability: The Causal Structure of Hunger and Famine' Progress in Human Geography 17.1: 43-67

Wynne, B. (1996) 'May the Sheep Safely Graze. A Reflexive View of the Expert-Lay Knowledge Divide', in S. Lash, B. Szerszynski and B. Wynne (eds) Risk, Environment and Modernity: Towards a New Ecology, London: Sage

- (1992) 'Uncertainty and Environmental Learning: Reconceiving Science and Policy in the Preventive Paradigm', Global Environmental Change 2.2: 111-127 